\title{
O DOM E A INICIAÇÃO REVISITADOS: O DADO E O FEITO EM RELIGIÕES DE MATRIZ AFRICANA NO BRASIL*
}

\author{
Marcio Goldman
}

Escutando Louis Armstrong [...], eu podia ouvir os espíritos mascarados falando, cantando, no modo como ele fazia soar esse instrumento europeu ocidental. Chinua Achebe

\section{O dom e a iniciação}

Como em qualquer campo de estudos, naqueles chamados de afro-brasileiros e, mais particularmente, no das religiões de matriz africana, existem alguns temas que parecem atrair a atenção dos pesquisadores e, por vezes, dos fiéis. Um deles é, sem dúvida, o das relações entre o que, nessas religiões, seria considerado como da ordem do "dom" e aquilo que elas pensam derivar do campo da "iniciação". Ou seja, relações entre o que o sujeito recebe independente de sua vontade e de suas ações - o "dado", como se costuma dizer - e o que depende de um conjunto de rituais mais ou menos tradicionais, que só podem ser desempenhados com o consentimento do sujeito e sob a condução de iniciados mais antigos do que ele — ou seja, aquilo que é "feito".

No entanto, entre os diversos temas que concentraram a atenção daqueles que estudaram as religiões de matriz africana no Brasil desde seu início, este possui uma relativa particularidade. Por um lado, o tema parece apresentar certa dificuldade "técnica" para os antropólogos, que não sabem muito bem se devem alinhá-lo do lado dos "fatos" (isto é, daquilo que, para nós, costuma ser o "dado") ou das "teorias" (os nossos "feitos"), como veremos adiante. Por outro lado, "o dom e a iniciação" afiguram-se também como objetos de atenção, reflexão e debate para os próprios fiéis - e isto em um duplo sentido: primeiro, porque se trata de uma questão cuja autenticidade, em tese, pode ou não ser atestada em casos concretos; em segundo, porque é objeto de constantes considerações abstratas e reflexivas. 
Ora, essa espécie de quadrangulação mais ou menos simétrica (fatos e teorias, dados e feitos, dos dois lados do processo de conhecimento) me parece fundamental, e é a partir dela que eu gostaria de explorar o tema. Para isso, usarei como ponto de partida metodológico um procedimento que, em outro lugar (Goldman 2008), denominei "confrontação". Ele consiste na tentativa de criação ou ativação de novas ideias e conceitos a partir de uma oposição intencional e mais ou menos forçada a ideias e teorias bem consagradas. Para isso, estas últimas podem até mesmo ser um pouco exageradas, como dizem Deleuze e Guattari (1980:362-363), mas não, frisam eles, "por provocação", e sim para que possam ser utilizadas "como um trampolim para saltar".

Meu "trampolim" será, mais uma vez, um artigo muito citado de Véronique Boyer - a quem peço desculpas antecipadas - publicado em 1996. Se em um trabalho recente (Goldman 2012), tentei recolocar a questão que constitui a segunda parte do título do artigo de Boyer ("o impacto da literatura sobre os cultos de possessão no Brasil"), o que pretendo aqui é retomar o problema levantado pela primeira parte deste título, "o dom e a iniciação". Em linhas muito gerais, Boyer sustenta que todas as religiões de matriz africana no Brasil estão mais ou menos dilaceradas entre o dom e a iniciação, ou seja, entre aquilo que derivaria "das capacidades pessoais que o médium manifesta em sua aprendizagem" e o que dependeria, antes, "da competência de um especialista religioso [...], de seu talento para explorar um conjunto de conhecimentos, formando um corpus ritual e doutrinário ao qual seus pares também se referem" (Boyer 1996:8).

Boyer certamente admite a existência de uma "complementaridade entre a iniciação e o dom", mas sugere que, para os fiéis, essa complementaridade pode (e talvez deva) ser quebrada: "alguns estão seguros de sua ligação com o que é da ordem da aptidão pessoal e inata, enquanto outros se pronunciam a favor de uma boa e correta iniciação". Os motivos para isso são localizados pela autora "na divergência entre os interesses dos chefes de culto, preocupados em consolidar sua ascendência sobre os médiuns que devem formar, e as aspirações destes últimos, desejosos de fundar um centro que lhes pertença" (Boyer 1996:8-9).

Ora, mesmo que tudo isso seja verdadeiro, deixa de lado uma série de pontos que eu gostaria de levantar. Em poucas palavras, trata-se apenas de indagar como "o dom e a iniciação" poderiam aparecer se, em lugar de reduzi-los a alguns de nossos hábitos intelectuais mais bem estabelecidos, fizéssemos um esforço para aceitar que o que está sendo dito pode ser bem diferente daquilo a que estamos acostumados. Ou seja, se fizermos um esforço para nos comportarmos como antropólogos. 
Roger Sansi deu um importante passo nessa direção. Em um texto sobre "dom, iniciação e historicidade nas religiões afro-brasileiras", ele parte das modalidades de relação com os espíritos isoladas por Boyer:

Há duas formas de fazer "santos", como Boyer já referiu [...]. Uma seria a capacidade inata, o "dom" para encontrar e incorporar espíritos - a mediunidade dos espíritas. A outra seria a "iniciação", o processo ritual através do qual a mãe de santo, como iniciadora, "põe a mão na cabeça", mostra os segredos do culto e dá os elementos necessários para que a pessoa "assente" os santos. O "dom" dos médiuns, por outro lado, permite produzir inovações rituais, produzir novos espíritos e novos elementos nos altares (Sansi 2009:139).

No entanto, Sansi pretende, em suas próprias palavras, "ir mais longe na distinção estabelecida por Boyer" (Sansi 2009:142). Se o entendi corretamente, trata-se de dar este passo, primeiro, reconhecendo que não há oposição, ou mesmo polaridade, entre as duas modalidades de relação: "não podemos simplesmente dizer que a iniciação se impõe ao dom, mas o fato é que eles estão mutuamente implicados" (Sansi 2009:142). Segundo, demonstrando a inadequação do tão difundido vocabulário do "capital simbólico" para descrever os inegáveis conflitos que se estabelecem em torno do dom e da iniciação. Afinal, diz o autor com precisão: trata-se do "que se é", não do "que se tem" (Sansi 2009:146) — uma vez que a pessoa, o dom que recebe das divindades e tudo o que adquire em sua iniciação compõem uma totalidade dificilmente decomponível. Em um vocabulário um pouco antigo, poderíamos dizer que cada um desses elementos "participa" dos demais.

\section{Nascer feito}

Meu objetivo aqui é apenas tentar dar mais um passo em relação ao que foi feito por Sansi. Pois enquanto ele se detém de bom grado na hipótese de que, em última instância, tanto o dom quanto a iniciação podem ser compreendidos como produto de uma história simultaneamente pessoal e coletiva (Sansi 2009:142, 151; ver, também, Sansi 2011), eu preferiria, antes, investir um pouco mais nessa ideia de uma participação entre os diversos elementos que compõem esse complexo simbólico. Para isso, eu gostaria de explorar alguns dados etnográficos antes de desembocar em qualquer tipo de conclusão. Lançarei mão, então, de uma série de informações mais ou menos dispersas por diversas fontes de diferentes proveniências — inclusive algumas obtidas por mim mesmo. 
Comecemos com o belo trecho de A cidade das mulheres, de Ruth Landes, no qual a antropóloga, acostumada a conviver com o que considera um dos mais tradicionais terreiros de candomblé de Salvador, conta como acabou por visitar certa Sabina, mãe de santo de um terreiro que Landes qualifica como da "tradição cabocla". A visita e os diálogos que compõem essa narrativa - com a incorporação do caboclo de Sabina e a desconfiança de Landes de que Sabina, travestida de caboclo, apenas deseja seu dinheiro - mereceriam uma análise detalhada, e mesmo um filme. Mas é claro que isto nos levaria longe demais e eu gostaria aqui apenas de assinalar o trecho em que Sabina pergunta à pessoa que conduzira Landes até ela se a convidada "sabe qual é a nossa seita? Sabe que somos caboclos e os outros são africanos?" (Landes 1994:175); que se trata de "uma casa de espíritos caboclos, os antigos índios brasileiros, e não vem dos africanos iorubás ou do Congo" (Landes 1994:176).

Vale a pena observar que Sabina não parece estar falando dos "caboclos" apenas para se referir aos espíritos com os quais trabalha, mas incluindo a si mesma e seu candomblé nesta categoria. Assim, quando Edison Carneiro, que acompanha Landes, pergunta, não sem segundas intenções, quem a havia iniciado, Sabina responde sem hesitar que "ninguém": "o senhor sabe que nós, as mães caboclas, não somos tocadas por mão humana. Quem me fez foi o espírito de um índio que veio a mim em sonho. Ele está morto há centenas de anos e ele é o meu guardião" (Landes 1994:159).

Trata-se, percebemos, da reivindicação, acionada por uma infinidade de adeptos de diferentes religiões de matriz africana no Brasil, de que é possível "nascer feito" ou, nos termos de Boyer, nascer com um dom tão poderoso que dispensaria qualquer iniciação. Reivindicação, acrescentam em geral os analistas, que serviria justamente para legitimar a posição daqueles que não teriam passado pelos procedimentos iniciatórios tidos como tradicionais. É exatamente o que Mãe Menininha do Gantois diz a Landes quando esta toca no nome de Sabina:

O que é essa mulher? [...] A senhora a chama de mãe? Ela quer é ganhar a vida, e não ajudar os outros, e nunca foi treinada em candomblé algum. Está atrás da sua carteira de dinheiro, minha senhora, e do prestígio do seu nome. E vive combatendo Constancia, que é uma grande mãe, porque Constancia a batizou na lei de caboclo. Constancia e Silvana, essas sim, são sacerdotisas! Silvana nunca precisou jogar os búzios para ver. Olhando para fora da sua casa, ela podia dizer tudo sobre qualquer um que estava passando [...]. Como a senhora pode falar de Sabina como mãe? Ela não liga nem para os deuses nem para as pessoas (Landes 1994:192). 
Há vários pontos interessantes na condenação de Mãe Menininha do Gantois a Sabina. Primeiro, não é o fato de pertencerem a diferentes nações do candomblé que pode explicar a dureza de suas palavras. Afinal, isso não a impede de reconhecer a seriedade e os poderes de Constancia e de Silvana. Poderes que, ao menos no caso desta última, dizem diretamente respeito à ordem do dom, uma vez que ela sequer precisa jogar os búzios para saber o que se passa com as pessoas... Simetricamente, o fato de ter sido iniciada por Constancia, que Mãe Menininha respeita, não impede que Sabina seja considerada uma aproveitadora desonesta. Mesmo que em outro momento ela diga a Landes que Sabina "cresceu selvagem! Nenhuma mão de mãe ou de santo a fez!" (Landes 1994:158).

Não creio que haja qualquer ambiguidade aqui. Jamais entenderemos o que quer que seja das religiões de matriz africana no Brasil se insistirmos em reduzir sua lógica àquela que preside nossos grandes sistemas teológicos ou morais, cujos princípios funcionam, ou deveriam funcionar, como premissas das quais podem ser deduzidos juízos particulares. Na verdade, o julgamento sobre Sabina não deriva automaticamente de outras situações, por mais parecidas que possam ser com a dela. Cada caso é mesmo um caso, e essa lógica polívoca e plural é mais uma demonstração daquilo que talvez possa ser considerada a única lei sociológica jamais isolada nos estudos sobre as religiões de matriz africana no Brasil:

Enfim, o supremo dispositivo compensador na estrutura do candomblé é encontrado em sua flexibilidade. Não há regra que não tenha sua exceção; em todas as circunstâncias, as situações alteram os casos. Essa tradição é básica na psicologia do candomblé; do ponto de vista da estrutura do candomblé, ela é um dos legados da tradição africana que constituiu uma das principais causas da sobrevivência dessa instituição complexa a despeito das pressões históricas a que foi submetida (Herskovits 1956:165).

A "lei de Herskovits" é de uma profundidade e de uma complexidade aparentemente ainda não percebidas pela maior parte dos pesquisadores das religiões de matriz africana no Brasil. Primeiro, porque coloca na própria estrutura dessas religiões aquilo que todos encontramos no campo, mas que costumamos atribuir a inconsistências ou manipulações: o fato de que "cada caso é um caso", ou o que poderíamos denominar de pragmatismo afro-brasileiro. ${ }^{1}$ Segundo, mas não menos importante, porque a sempre polêmica "tradição" é pensada como parte da "psicologia do candomblé", não de uma história "lá fora" que poderia ou não ser verificada: a tradição é uma intenção que também se encontra na "estrutura do candomblé" e que, ponto crucial, é fundamental para a sua resistência. 
Ora, é essa mesma lógica pragmática e polívoca que permite a Esmeraldo Emeterio de Santana (1984), grande tata do terreiro angola Tumbajunçara de Salvador, lembrar Joãozinho da Gomeia — que Bastide (2000:316) qualifica (ou diz que qualificam) como "um dos babalorixás clandestinos", "feitos do pé para a mão" - alguém que jamais teria sido iniciado adequadamente e, ao mesmo tempo, um dos grandes sacerdotes de sua nação, uma vez que teria contribuído como poucos para o crescimento do candomblé angola no Brasil.

Assim, se não há nenhuma dúvida de que a afirmação do "nascer feito" pode ser, e efetivamente é, acionada como meio de afirmar sua própria força quando o recurso à tradição parece impossível ou ineficaz - como estratégia de legitimação, se assim se quiser denominá-la — é evidente que isto não significa que "nascer feito" não seja uma possibilidade profundamente ancorada nos princípios ontológicos e cosmológicos das religiões de matriz africana no Brasil. Vivaldo da Costa Lima (2003:149) conta, por exemplo, que Mãe Senhora, do arquitradicional terreiro ketu Axé do Opô Afonjá, de Salvador, estranhava a necessidade de um ritual específico para conceder a um iniciado de certa senioridade o direito de passar a iniciar outras pessoas (o decá da tradição ketu, ou sakafunã da angola). Afinal, pondera o autor, ela recebera a navalha iniciatória de sua avó das mãos de sua própria mãe, sem necessidade, portanto, de um rito especial. Isso faria, conclui Lima (2003:149), que "o caso raro que fora o seu, recebendo o posto através da linhagem de sua avó, para ela constituía a norma que devia ser obedecida por todos".

Que casos deste tipo não são assim tão raros é o que veremos adiante. Antes, contudo, vale a pena nos determos rapidamente no fato de que em inúmeras cosmologias africanas e de matriz africana existe uma categoria de indivíduos que, do ponto de vista nativo, em certo sentido "nascem feitos". São os chamados abikus, termo iorubá que significa literalmente "o que nasce para morrer". Em princípio, trata-se de crianças que nascem, morrem e renascem continuamente até que algum procedimento ritual seja capaz de mantê-las neste mundo. No meu próprio campo, e creio que em outros lugares, essa proximidade excessiva com a morte é interpretada também como uma espécie de vínculo já dado com uma divindade, a qual, portanto, insiste em reclamar a criança para o seu mundo. É possível, evidentemente e como sempre nas religiões de matriz africana no Brasil, negociar ritualmente com a divindade a sobrevivência da criança, mas uma das condições dessa sobrevida é justamente que a criança não seja iniciada. Em certo sentido, penso, porque ela já "pertence" a uma divindade; em outro, porque não parece adequado, ou mesmo possível, "fazer" (iniciar) aquilo que, paradoxalmente, é "dado" como já "feito". ${ }^{2}$ 
Nesse mesmo campo parecem se localizar os casos chamados de "santo de herança", ou seja, divindades já "prontas" ou já "feitas" que são transmitidas a um descendente, ou mesmo a pessoas apenas próximas, após o falecimento do transmissor. Este era, por exemplo, o caso de Joãozinho da Gomeia que, além de sua própria divindade, herdou o orixá de sua madrinha, cujo assentamento ele se orgulhava em apresentar, dizendo que "esse orixá tem 94 anos" (Cossard 1970:140; ver, também, Cossard 1970:247, 280).

Como mostrou Serra, se o termo orixá pode perfeitamente ser usado no lugar de santo, o inverso nem sempre é verdadeiro. Isto porque o termo orixá costuma ser reservado para

a divindade em sua feição mais transcendente, enquanto "invisível" ou não "fixada" - através do rito adequado — numa cabeça devota [...]. Este ser está ao lado de todo homem, como "anjo da guarda", antes de qualquer iniciativa religiosa, [mas] só quem se iniciou tem santo, e várias pessoas podem pertencer a um mesmo Orixá, mesmo assim os santos delas serão diferentes ao virem à luz da camarinha - tão distintos quanto as cabeças consagradas dos "filhos" (Serra 1978:59-60).

Por outro lado, como vimos, os santos já feitos podem sobreviver à morte de seus devotos, e é esta possibilidade que permite a Esmeraldo Emeterio de Santana chegar a aventar a incomum hipótese de uma finitude do número desses santos, duvidando discretamente da viabilidade de se fazerem santos realmente novos:

Não há mais "santo" sem fazer, eles já são todos "feitos" [...]. A gente, que labuta tantos anos com "santo" de candomblé, vê que, às vezes, o "santo" é a mesma coisa do finado fulano. Fala, gesto, a gente fica pensando. Será o espírito de fulano? E, se eu voltar, e alguns de vocês estiverem vivos, eu hei de dizer: "Sou eu" (Santana 1984:47).

\section{Sangue, iniciação, participação}

Em suma, não é muito difícil encontrar aquilo que para um olhar excessivamente extrínseco tende a surgir apenas como invenção da tradição ou manipulação micropolítica no coração mesmo dos princípios ontológicos e epistemológicos das religiões de matriz africana no Brasil. Entretanto, antes de prosseguir nessa direção, é preciso ainda insistir um pouco sobre um ponto da mais alta relevância. 
Na excepcional monografia que escreveu sobre o candomblé em Recife, Arnaud Halloy toca em um aspecto absolutamente essencial para essa discussão. Trata-se, em princípio, de uma espécie de polêmica entre sacerdotes de uma mesma família, simultaneamente de santo e de sangue, acerca da necessidade de eles terem que se submeter ao processo de iniciação. Descendentes "legítimos" do famoso Pai Adão, alguns deles sustentam que, sendo "pessoas de raiz" em função de sua "ascendência africana" (Halloy 2005:638), "nós já nascemos 'feitos'... Nós devemos fazer apenas o 'complemento'... Porque nós já nascemos prontos... Nós temos uma descendência muito forte... Nós só precisamos completar, pois isso faz parte do 'preceito' religioso... Nós prestamos esse culto desde o berço" (Halloy 2005:640). Outros acrescentam que, a despeito de tudo, a iniciação não deixa de ser essencial - ainda que a justificativa para isto possa não ser a que poderíamos esperar: todos deveriam se iniciar porque seus próprios antepassados também se iniciaram (Halloy 2005:641-642).

Encontrei uma configuração muito parecida com esta no Matamba Tombenci Neto, terreiro de candomblé da nação angola, situado em Ilhéus, no sul da Bahia, onde concentro, há muito tempo, as minhas investigações (Goldman 2005, 2009). De nação diferente dos terreiros estudados por Halloy (que se definem como "nagô"), o Tombenci, não obstante, também é estruturado a partir de uma base familiar, ainda que esta apresente uma inflexão matrilateral - e não patrilateral, como em Recife. Essa matrilinhagem remonta à avó de sangue da atual mãe de santo, tendo passado por seu tio materno e por sua mãe biológica antes de chegar a ela que, com quase 80 anos de idade, tem 14 filhos, dezenas de netos e alguns bisnetos.

A mãe de santo do Tombenci também me explicou que, rigorosamente falando, seus filhos carnais não precisariam ser iniciados, ainda que ela prefira fazê-lo a fim de evitar falatórios, intrigas e fofocas. A justificativa por ela apresentada para esta não necessidade parece, ao menos em uma primeira leitura, diferente daquela encontrada por Halloy. Tendo nascido e crescido no terreiro, e tendo sido, por isso mesmo, compelidos a participar de uma série de atividades rituais, mais ou menos cotidianas, que exigem preparação prévia, seus filhos teriam, na verdade, passado ao longo do tempo, de forma intermitente e nem sempre pública, por todas as etapas que constituem o processo iniciatório. Desse modo, sua iniciação propriamente dita consistiria em uma recapitulação sintética de tudo o que já foi feito ao longo dos anos e em uma demonstração de rigor diante daqueles mais interessados em intrigas.

A partir do riquíssimo material que reuniu em Recife, Halloy acreditou ter encontrado dois modos fundamentais de "transmissão de saber" 
no candomblé. Um que ele chama de "herança pelo sangue", e outro que denomina "transmissão por participação" (Halloy 2005:644). Halloy caracteriza, entre aspas é verdade, a primeira concepção como de caráter "essencialista" ou "biológico", e a segunda como "culturalista" (Halloy 2005:645), reconhecendo, ao mesmo tempo, que no discurso de seus amigos elas "são frequentemente confundidas ou justapostas, sem que essa ambiguidade seja esclarecida" (Halloy 2005:644):

Dois modos de transmissão religiosa são normalmente distinguidos em minha família de santo. O primeiro, que seria específico dos descendentes biológicos do Pai Adão, é concebido sob o modo da "herança": de maneira quase atávica, os saberes religiosos são transmitidos "pelo sangue" de uma geração de chefes de culto à seguinte. O segundo modo sublinha a importância da iniciação e acentua a necessidade de transmitir [passar] os saberes. Trata-se de duas tendências explicativas, não de distinções marcadas [...] (Halloy 2005:681).

Por outro lado, a rica descrição etnográfica apresentada por Halloy e mesmo parte de sua interpretação apresentam uma terceira concepção, à qual, creio, o autor não dedica a devida atenção. Trata-se do que os membros dos terreiros que ele estudou denominam "convivência", e que Halloy lembra, com razão, significar "literalmente o fato de 'viver com'" (Halloy 2005:642). Nesse ponto, entretanto, essa noção de convivência acaba sendo rebatida na de "participação", que havia sido anteriormente isolada. Ao fazêlo, acredito que Halloy perde de vista o que penso ser o caráter triádico do modelo nativo - ao menos em sua formulação inicial.

O problema, penso, deriva do fato de que o termo "participação" acaba sendo reduzido pela análise ao seu sentido sociológico quando sabemos que, de fato, ele também pode ser entendido em uma acepção propriamente ritual. "Participar" não é apenas "conviver", mas também entrar em relação, material ou não, com aquilo que constitui o ritual. Isto significa que a "transmissão por participação" diz respeito tanto ao que se aprende enquanto membro de um terreiro quanto ao que se recebe na iniciação propriamente dita. Sangue, ritual e convivência constituiriam, assim, os vértices de um modelo triangular que colocaria em xeque a concepção dualista de Boyer. Se os dois primeiros termos de Halloy (sangue e ritual) podem, aparentemente, ser associados ao dom e à iniciação de Boyer, o estatuto do terceiro a convivência ou participação - permanece mais indefinido. Evitemos aqui, contudo, o vício profissional que nos levaria a apenas acrescentar uma dimensão "sociológica" ao par "biológico-cultural" inicial. Muito pelo contrário, creio que o terceiro elemento permite justamente o passo essencial: 
a percepção do caráter em última instância monista do sistema — ainda que esse monismo de base seja apenas a resultante de uma multiplicidade intensiva de linhas de forças e vetores.

Em sua bela etnografia sobre candomblés na periferia da Grande Salvador, Jim Wafer conta que uma cadela de um dos terreiros que pesquisou era "considerada quase uma iniciada - mesmo que não tivesse sido 'raspada' — porque passara algum tempo em reclusão com dois diferentes barcos de iaôs" (Wafer 1991:138). Em chave um pouco mais séria, o fato de ter caído dentro de uma bacia com oferendas a Xangô durante sua reclusão iniciatória na infância no Tombenci fez com que uma filha de Iansã se visse obrigada, pelo resto de sua vida, a oferecer uma refeição por ano a este orixá, o qual, no entanto, não se conta entre aqueles a quem ela foi consagrada.

Durante muitos anos, os animais que esperavam para ser sacrificados eram amarrados em duas jaqueiras localizadas naquela que então era parte da "roça" do terreiro Tombenci Neto. Derrubadas quando uma nova rua atravessou o terreno, as árvores tiveram seus troncos guardados durante anos por decisão da mãe de santo. Em 1999, ela pediu a um dos amigos da casa, artista plástico que se dedica à elaboração de lindíssimos móveis rústicos ecológicos, que transformasse um dos troncos em um "trono", no qual ela passou a se sentar para comandar as cerimônias públicas no terreiro. A impressionante peça foi recortada com uma motosserra, e os restos da madeira distribuídos pela mãe de santo entre membros do terreiro por concentrarem muita força e, consequentemente, serem capazes de ajudar aqueles que os conservassem em casa.

Em 2002, o que parecia ser apenas uma brincadeira em meio a muita comida e bebida à sombra de um jambeiro plantado em 1996 na frente do terreiro se converteu, rapidamente, em um "batizado", no qual a árvore recebeu um padrinho e uma madrinha, que se somaram ao pai e à mãe da árvore, ou seja, àqueles que a haviam plantado seis anos antes. Intrigado com a aparente solenidade de que a brincadeira havia se revestido, perguntei mais tarde se o jambeiro era uma árvore especial, consagrada a alguma divindade. Responderam-me que não necessariamente, mas que todas as árvores que são plantadas na área de um terreiro de candomblé vão se tornando especiais à medida que absorvem a força das oferendas e das pessoas que por ali passam.

Ainda que algumas dessas histórias, que se contam às centenas, possam ser consideradas simples "brincadeiras", elas não deixam de revelar algo sobre a lógica subjacente ao triângulo isolado por Halloy em Recife. De mim mesmo disseram diversas vezes em Ilhéus que, embora não tivesse sido iniciado, eu "andava por lá há tanto tempo" que podia ser considerado "da 
casa". O que poderia ser tomado apenas como cortesia (e que certamente o era) tinha, contudo, consequências rituais bem mais sérias: em diversas ocasiões me vi em situações das quais, em tese, eu não poderia participar em virtude do fato de não ter sido iniciado.

A hipótese aqui em jogo, portanto, é a de que o caráter aparentemente triádico do modelo nativo não apenas contesta o dualismo dos antropólogos, como oculta, na verdade, um monismo de base. Isto porque o que Halloy denomina "herança pelo sangue" e o que eu mesmo desdobrei em "participação-sociológica" e "participação-ritual" têm um mínimo denominador comum. Ou, para ser mais preciso, constituem atualizações de um princípio subjacente único. Afinal, sabemos bem que os centros de culto das religiões de matriz africana no Brasil poderiam perfeitamente ser compreendidos como enormes máquinas destinadas à captação, à distribuição e à circulação da força única que, em suas cosmologias, constitui tudo o que existe e pode existir no universo. Como escrevi em outro lugar, essa força - o axé, dos candomblés ketu, ngunzo, dos angola, ou simplesmente força, energia, em inúmeras outras religiões deste tipo - "constitui tudo o que existe e pode existir no universo, seguindo um processo de diferenciação e individuação", sua unidade garantindo "que tudo participa de tudo" e suas modulações fazendo "com que haja graus de participação" (Goldman 2009:123).

Há mais, contudo. Juana Elbein dos Santos (1977:37-43) demonstrou que essa força única e múltipla tem um modo de circulação fundamental: o "sangue". Palavra que, entretanto, não significa exatamente nesse contexto o que poderíamos imaginar. Pois esse sangue não é apenas o que nós mesmos chamamos de sangue: ele pode ser vermelho, branco e preto e ele se distribui entre os reinos animal, vegetal e mineral, gerando assim nove possibilidades das quais nós só retemos uma: "o 'sangue' vermelho [...] do reino animal: corrimento menstrual, sangue humano ou animal" (Elbein dos Santos 1977:41).

Ora, isso só pode significar que o sangue que recebo dos meus antepassados, aquele que recebo na iniciação e aquele que flui na convivência cotidiana - seja o das plantas e o dos animais consagrados ao longo dos anos no terreiro, seja o dos alimentos que compartilho nas refeições coletivas, seja simplesmente o das pessoas, divindades e espíritos com quem convivo são, de certo ponto de vista, uma única e mesma coisa.

Entretanto, não é apenas o "sangue" (ou seja, o "dado") que é mais complicado do que poderíamos imaginar. Creio que minha hipótese permite também compreender melhor - ao mesmo tempo em que é mais bem compreendida - o fato de que parecem existir, grosso modo, pelo menos dois modelos de iniciação (do "feito") nas religiões de matriz africana no 
Brasil. Esses modelos não se apresentam da mesma forma, nem com a mesma nitidez, intensidade e grau de institucionalização em todas as variantes dessas religiões, mas penso que, de um modo ou de outro, as permeiam de ponta a ponta. Utilizarei aqui um dos modelos que me parecem mais explícitos, o do chamado "candomblé da Bahia", ${ }^{3}$ especialmente claro nas "grandes" casas de santo de Salvador, mas que também foi o que encontrei no Tombenci, em Ilhéus. O fato de ele não ser encontrado de maneira tão nítida em outros lugares não significa, portanto, que sua estrutura de base não esteja aí presente.

O primeiro modelo de iniciação, que poderíamos chamar iniciação estrito senso, consiste no que se denomina, nesse "candomblé baiano", "feitura do santo", processo que, como sabemos, corresponde simultaneamente à "feitura da cabeça", ou seja, à constituição de uma nova pessoa (Goldman 1984, 1985). Creio que o fato de esse modelo soar menos estranho a nossas próprias concepções acerca da produção e da propriedade das coisas explica que ele tenha sido privilegiado na maior parte dos estudos afro-brasileiros - o outro modelo, do qual já falarei, tendo sido usualmente considerado impuro, residual ou meramente estratégico, dependendo dos autores. Costuma-se mesmo insistir, e muito, sobre a dimensão de morte e renascimento desse processo iniciatório, sem se prestar a devida atenção ao fato de que, ainda que essa associação seja indubitavelmente verdadeira, ela não resolve nenhum problema, pois, afinal, tudo dependeria ainda das concepções nativas acerca dessa morte e desse renascimento, concepções que, como sabemos, pouco têm a ver com nossas ideias a respeito de fins e começos absolutos.

Mas existe outro modelo de iniciação acionado ao menos em boa parte desse "candomblé da Bahia". Ele funciona em geral, mas não apenas, para o caso de pessoas que, como o autor destas linhas, não possuem o "dom" para receber os santos em seus corpos, ou seja, que não são capazes de entrar em transe e experimentar a possessão divina. Na Bahia, essas pessoas são geralmente chamadas de ogãs ou tatas, quando do sexo masculino, e de equedes ou muzenzas, quando do sexo feminino (nas nações ketu e angola, respectivamente). Ao contrário de uma hipótese narcisista muito repetida, esses cargos, funções ou dons não foram inventados apenas para receber intelectuais e brancos em geral no candomblé, mas simplesmente estendidos a eles, uma vez que já existiam há muito tempo nos terreiros. Eles recobrem atividades como o toque dos atabaques, o canto ritual, os sacrifícios, o cuidado das pessoas em transe, e assim por diante. ${ }^{4}$

De todo modo, o ponto central aqui é que, embora se diga às vezes que um ogã ou uma equede são feitos, o mais usual, ou talvez o mais preciso, é 
dizer que eles são, primeiro, suspensos para, em seguida, serem confirmados. A suspensão ocorre, via de regra, em meio a uma cerimônia pública, não especificamente voltada para esse fim, quando uma das divindades incorporadas escolhe uma pessoa presente, caminha com ela pelo barracão e a faz sentar-se em uma cadeira que será suspensa pelos ogãs mais antigos presentes. Com o tempo, imagina-se que o ogã ou a equede suspenso/a deverá confirmar ritualmente sua iniciação, passando por uma sequência ritual semelhante, mas com algumas importantes diferenças daquela empregada na feitura da cabeça propriamente dita. Como escutei de um pai de santo que ordenava a todos os presentes - alguns com mais de meio século de iniciação! — que se ajoelhassem e pedissem a bênção a dois ogãs que acabavam de ser suspensos, "ogã não é como iaô, que nasce pequeno e cresce depois; ogã já nasce grande!".

Ora, se aceitarmos o fato de que nas religiões de matriz africana no Brasil o processo de criação não é pensado nem segundo a lógica judaico-cristã da criação ex nihilo, nem segundo o modelo hilemórfico grego clássico (no qual uma forma criadora é aplicada a uma matéria inerte), talvez possamos levantar a hipótese de que a "confirmação" seja um modelo mais adequado do que a "feitura" para pensarmos o processo de iniciação em geral. Isto porque, como tentei demonstrar em outro lugar (Goldman 1984, 2005), nessas religiões todos os seres já existem de alguma forma, mesmo antes de serem feitos. O que significa, penso, que o processo de criação é aí entendido como a revelação das virtualidades que as atualizações dominantes contêm, no duplo sentido do termo.

Sendo assim, a diferença entre ogãs e equedes, de um lado, e "rodantes" (como se denomina os suscetíveis ao transe), de outro, seria mais de grau do que de natureza: uns já "nascendo grandes", os outros tendo que "crescer" para isso. Ou, em termos mais abstratos: uns já nascendo com suas virtualidades mais atualizadas, os outros tendo que atualizá-las progressivamente ao longo da vida. Isto, ademais, talvez servisse para melhor explicar esta questão do que as acusações de simples erro ou manipulação dos inúmeros casos conhecidos de ogãs e equedes que passam a entrar em transe em algum momento de suas vidas. E também as variantes etnográficas (registradas por Halloy em Recife e por outros autores em outras regiões) em que, mesmo que a distinção entre rodantes e não rodantes não seja institucionalmente marcada, se reconhecem maiores e menores suscetibilidades ou dons para o transe e a possessão.

É por isso, também, que na vida cotidiana a questão do dom constitui justamente uma questão — ou seja, algo aberto à reflexão, ao debate e à discordância. O fato de Mãe Menininha do Gantois não acreditar nos dons 
de Sabina não significa, é claro, que ela não acredite naqueles de Silvana ou de Mãe Senhora e, a fortiori, na possibilidade do dom em geral. E quando Bastide insinua que Joãozinho da Gomeia seria "um dos babalorixás clandestinos", "feitos do pé para a mão", seria preciso distinguir se isso lhe foi apresentado como regra geral, o que duvido, ou como um juízo muito específico sobre uma pessoa bem concreta em determinado momento, no que eu apostaria.

E eu também apostaria que qualquer um, ao menos no "candomblé da Bahia", acharia muito estranha a ideia de iniciar alguém que não tivesse o dom para as coisas da religião. Como se sabe, se há algo com que todos parecem concordar é que ninguém se inicia no candomblé "porque quer", mas porque sua iniciação é exigida pelo seu orixá. Por outro lado, creio que meus amigos também considerariam muito estranha, ou ao menos duvidosa, a possibilidade de existir alguém cujos dons sejam tão fortes que dispensariam qualquer iniciação. Em suma, a relação entre dom e iniciação não é nem da ordem da oposição, nem da redundância, nem da causalidade direta. Se quiséssemos empregar um conceito fora de moda, poderíamos talvez dizer que se trata de uma complementaridade dialética. Mas isto não ajudaria muito, pois o problema da dialética, como observou Deleuze, é não perceber que o importante não está nem nos termos, nem em sua contradição, nem em sua possível ou impossível síntese:

O que conta [...] não é o 2 ou o 3, ou sei lá quanto, é o $E$, a conjunção $E[\ldots]$. $O E$ é a diversidade, a multiplicidade, a destruição das identidades [...]. O E não é nem um nem o outro, é sempre entre os dois, é a fronteira, sempre há uma fronteira, uma linha de fuga ou de fluxo, mas que não se vê, porque ela é o menos perceptível. E no entanto é sobre essa linha de fuga que as coisas se passam, os devires se fazem [...] (Deleuze 1976:64-66).

\section{Observações finais}

Para terminar, coloquemos uma questão de ordem, digamos, "epistemológica": de onde poderia provir, então, essa hipótese de um par "dom e iniciação" em que a conjunção "e" desempenha muito mais a função do adversativo "ou"? Ou melhor: de onde poderia provir o sucesso e a facilidade com que costuma ser aceita essa hipótese? Não vou apelar aqui para noções como campo intelectual e congêneres, simplesmente porque não me parece muito difícil adivinhar as razões desse sucesso em um plano propriamente cosmológico ou, de forma mais precisa, naquele do confronto de duas cosmologias. 
Como vimos, quase todos que se referem a essa oposição tendem a assimilar, em maior ou menor grau, o "dom" ao "inato" e a "iniciação" ao "adquirido". O que faz, claro, com que a dicotomia se assemelhe quase à perfeição a nossos modos dominantes de pensar - e "nossos" tanto no que se refere ao chamado "senso comum" quanto no que diz respeito ao próprio pensamento antropológico. Afinal, como sabemos, ao menos desde Tylor, a antropologia se define como o estudo do "adquirido" em oposição ao "inato". Ou, alternativamente, como a descoberta do que poderia haver de "inato" para além ou sob o "adquirido".

Claro que todos também sabemos que já há algum tempo esse modelo vem sendo posto em questão dentro e fora da disciplina. É provável que a última, e mais interessante, tentativa antropológica de repensar a "cultura" (ou seja, o "adquirido") seja aquela empreendida, a partir de meados da década de 1970, por Roy Wagner. Grosso modo, trata-se da elaboração de uma noção de cultura que poderíamos chamar de propriamente cultural, no sentido em que dela faz parte intrínseca e constitutiva a explicitação de que a noção de cultura é ela mesma um artefato cultural, ou seja, que ela é produto de um ponto de vista cultural específico - o nosso. Este é, parece-me, o sentido da expressão "invenção da cultura" (Wagner 1981, capítulo 1).

No entanto, mesmo esse construtivismo aparentemente absoluto de Wagner parece se deter em uma espécie de universal: a distinção, diferentemente marcada segundo as "culturas", entre o que depende da ação humana e o que se impõe a ela (Wagner 1981:19). Como resumiu com perfeição Eduardo Viveiros de Castro, trata-se "de saber o que seria o dado do melanésio" (ou seja, de qualquer nativo):

Tal questão, convenhamos, não é irrelevante. Se é verdade que "a antropologia procura elaborar a ciência social do observado" (Lévi-Strauss), então uma de nossas tarefas principais consiste em elucidar o que, para os povos que estudamos, faz as vezes de dado - de fato inato que circunscreve e condiciona a agência humana - e o que, correlativamente, é percebido como construível ou feito, isto é, como pertencendo à esfera da ação e da responsabilidade dos agentes (Viveiros de Castro 2002:404).

O uso do termo "inato" assinala aqui, é claro, que dado e feito são, de início, analogias, no sentido wagneriano da expressão: distinção nossa que, estendida aos outros, serve para dar inteligibilidade a processos de difícil compreensão, mas que deve ser subvertida ao longo do processo (Wagner 1981:16-17). Mas, apesar de tudo, eu arriscaria dizer que subsiste no pensamento de Wagner certa tensão entre conceber o dado e o feito como tipos 
ou como forças. E ainda que eu acredite que a posição de Wagner seja a segunda, nem estou absolutamente certo disso, nem adianta muito atribuir os mal-entendidos em torno deste ponto apenas à suposta estupidez de alguns leitores (ver Goldman 2012).

Desse modo, se tentássemos "aplicar" essas ideias de Wagner às religiões de matriz africana no Brasil, ficaríamos diante de duas possibilidades. Por um lado, poderia parecer que a teoria wagneriana simplesmente "não se aplica" a essas religiões. Por quê? Porque parece muito difícil detectar com precisão aquilo que, nelas, faria as vezes de "dado", ou seja, do que se encontra fora do alcance da ação humana. Por certo ninguém imagina que seja possível fazer qualquer coisa, mas o interessante é que o impossível só surge a posteriori, depois de um eventual fracasso. Além disso, nada parece, tampouco, ser integralmente "feito", uma vez que tudo o que é feito deve ser continuamente refeito e depende de pré-constrangimentos "dados".

Esse falso problema apenas revela o ponto mais geral que eu gostaria de levantar: a necessidade de uma espécie de esforço suplementar para tentar deixar de pensar nossas teorias como nossos feitos, que aplicamos a dados que podem ou não confirmá-las. Na antropologia, como insinuei desde o início, o problema é o do alinhamento de conceitos presentes dos dois lados do processo de conhecimento. Desse ponto de vista, creio, tudo poderia ser formulado de outra maneira e, para concluir, eu gostaria de propor uma espécie de esboço do que poderia ser uma tentativa de realinhamento conceitual entre a antropologia e as religiões de matriz africana no Brasil.

De um lado, poderíamos tratar o construtivismo radical das religiões de matriz africana como uma daquelas dialéticas sem síntese — na acepção wagneriana da expressão (Wagner 1981:96, entre outras) — entre o dado e o feito. Por outro, contudo, deveríamos reconhecer que o pensamento wagneriano (ou qualquer pensamento) não pode passar incólume pelo confronto com o pensamento afro-brasileiro, e que a leitura do segundo pelo primeiro implica necessariamente uma leitura de Wagner deste segundo ponto de vista. Nesse sentido, como insinuei acima, essa dialética sem síntese poderia ser repensada. Não se trata tanto, penso, de uma afirmação infinita e irresolúvel de dois ou mais termos; trata-se, antes, como sugeriu Deleuze, de uma afirmação do E como conectivo, no nosso caso, de uma espécie de hiperaceleração das relações entre o dado e o feito. Ou, para ser um pouco mais preciso, como um conjunto ininterrupto de operações de variação contínua. ${ }^{5} \mathrm{O}$ dom $E$ a iniciação, o dado $E$ o feito, a iniciação $E$ o dado, o feito $E$ o dom... No final das contas, qualquer um que conheça as religiões de matriz africana no Brasil se perguntaria como isso poderia ser diferente... 
Finalmente, para dar uma última volta no parafuso, penso que este modelo poderia ricochetear na direção da própria antropologia. Nesse sentido, nossas teorias não são simplesmente os nossos "feitos", e os fatos não são apenas os nossos "dados". Teorias e fatos são, de algum modo, imanentes uns aos outros, e o que nos cabe fazer, com dizem as mães de santo e os escultores, é "lapidá-los", ou seja, passar ininterruptamente em variação contínua de uns a outros, fazendo-os surgir de modo razoavelmente inteligível do bloco em que já estavam contidos - no duplo sentido desta palavra.

Recebido em 09 de março de 2012

Aprovado em 14 de agosto de 2012

Marcio Goldman é professor associado do Programa de Pós-Graduação em Antropologia Social, Museu Nacional, Universidade Federal do Rio de Janeiro; pesquisador do CNPq e bolsista da Faperj. E-mail: <marcio.goldman $@$ gmail.com>

\section{Notas}

*Versões preliminares deste artigo foram apresentadas, em 2009, no seminário “Territórios Sensíveis: Diferença, Agência e Transgressão", no Museu Nacional, Rio de Janeiro, no painel "A Experiência Religiosa e suas Delimitações"; no IV Congresso da Associação Portuguesa de Antropologia, em Lisboa; e em 2012, como conferência de abertura do ano acadêmico do PPGAS/UFRGS (além de, em 2010, nos seminários "Sextas na Quinta" do Núcleo de Antropologia Simétrica, PPGAS, Museu Nacional, Rio de Janeiro). Agradeço, respectivamente, a Olívia Gomes da Cunha, a Susana Viegas e a Sergio Baptista da Silva pelos convites para participar desses eventos. Também a Emerson Giumbelli e Roger Sansi pelos comentários no Rio e em Lisboa; a Ruy Blanes e Diana Espírito Santo, pelos comentários no evento em Lisboa; e aos participantes do NAnSi pela "Sextas na Quinta". Eu gostaria, finalmente, de agradecer em especial a Paula Siqueira, Gabriel Banaggia e José Antonio Kelly pelos comentários que me ajudaram a aprimorar o texto.

${ }^{1}$ Entendendo pragmatismo, claro, em seu sentido filosófico mais sério: "o pragmatismo é uma arte das consequências, uma arte do ser cuidadoso" (Pignarre \& Stengers 2005) — e não uma questão de princípios ou de moral. 
${ }^{2}$ Ver Verger (1983). E também, entre outros, Johnson (2002:121, 126, 201); Lima (2004:206-207); Rabelo (2008a:107-108, 114); Rabelo (2008b:181, 203); Wafer (1991:139).

${ }^{3}$ Uso esta expressão no sentido que lhe é conferido por Serra (1995:40-44): o de um "'modelo' [que] não quer dizer 'figurino' ou 'protótipo' ortodoxo, nem corresponde a um rito particular, à liturgia desse ou daquele terreiro. O modelo [...] é uma abstração construída a partir do estudo comparativo de diferentes ritos".

${ }^{4}$ Minha função, por exemplo, me foi explicada como um "tipo de relações públicas do terreiro".

${ }^{5}$ O conceito de variação contínua foi introduzido por Deleuze e Guattari (1980:117-139, principalmente) como uma forma de contornar a hipótese de que a linguagem seria um sistema fechado, homogêneo, constante e universal. Ao contrário, sustentam os autores, as falas estão sempre em variação contínua, alternando "regras variáveis e facultativas" e se movendo ininterruptamente entre diferentes registros da linguagem.

\section{Referências bibliográficas}

BASTIDE, Roger. 2000 [1958]. Le candomblé de Bahia (rite nagô). Paris: Plon. BOYER, Veronique. 1996. "Le don et l'initiation: de l'impact de la littérature sur les cultes de possession au Brésil". L'Homme, 138:7-24.

COSSARD, Gisèle B. 1970. Contribution à l'étude des candomblés du Brésil: le rite angola. Tese de Doutorado, Sorbonne, Paris.

DELEUZE, Gilles. 1990 [1976]. "Trois questions sur six fois deux (Godard)". In: Pourparlers 1972-1990. Paris: Minuit. pp. 55-66.

DELEUZE, Gilles \& GUATTARI, Félix. 1980. Mille plateaux. Paris: Minuit.

ELBEIN DOS SANTOS, Juana. 1977. Os Nagô e a morte. Padê, axexê e o culto egum na Bahia. Rio de Janeiro: Vozes.
GOLDMAN, Marcio. 1984. A possessão e a construção ritual da pessoa no candomblé. Dissertação de Mestrado, Programa de Pós-Graduação em Antropologia Social, UFRJ, Rio de Janeiro. 1985. "A construção ritual da pessoa: a possessão no candomblé". Religião e Sociedade, 12(1):22-54.

- 2005. "Formas do saber e modos do ser: observações sobre multiplicidade e ontologia no candomblé". Religião e Sociedade, 25(2):102-120.

- 2008. "Os tambores do antropólogo: antropologia pós-Social e etnografia". Ponto Urbe. Revista do Núcleo de Antropologia Urbana da USP, 2(3), julho 2008. Disponível em: http://www.n-a-u.org/pontourbe03/ Goldman.html\#3. Acesso em: 09 de março de 2012. 
2009. "Histórias, devires e fetiches das religiões afro-brasileiras. Ensaio de simetrização antropológica". Análise Social, XLIV(190):105-137.

2012. "O fim da antropologia". Novos Estudos CEBRAP, 89:195-211.

. 2012. "Cavalo dos deuses: Roger Bastide e as transformações das religiões de matriz africana no Brasil". Revista de Antropologia, 54(1) (no prelo).

HALLOY, Arnaud. 2005. Dans l'intimité des orixás. Corps, rituel et apprentissage religieux dans une famille-desaint de Recife, Brésil. Tese de Doutorado, ULB/EHESS, Bruxelles/Paris.

. 2010. "'Chez nous, le sang règne!'. L'apprentissage religieux dans le culte xangô de Recife". Terrain, 55: 40-53.

HERSKOVITS, Melville J. 1956. "The social organization of the afrobrazilian candomble". Phylon, 17(2):147-166.

JOHNSON, Paul Christopher. 2002. Secrets, gossip, and gods: the transformation of brazilian candomble. Oxford: Oxford University Press.

LANDES, Ruth. 1994 [1947]. The city of women. Albuquerque: University of New Mexico Press.

LIMA, Vivaldo da Costa. 2003 [1977]. A família de santo nos candomblés jejes-nagôs da Bahia: um estudo de relações intragrupais. Salvador: Corrupio.

—. 2004. "O candomblé da Bahia na década de 1930". Estudos Avançados, 18(52):201-221.

PIGNARRE, Philippe \& STENGERS, Isabelle. 2005. La sorcellerie capitaliste: pratiques de désenvoûtement. Paris: La Découverte.

RABELO, Miriam. 2008a. "A possessão como prática: esboço de uma reflexão fenomenológica". Mana. Estudos de Antropologia Social, 14(1):87-117.
_ 2008b. "Entre a casa e a roça: trajetórias de socialização no candomblé de habitantes de bairros populares de Salvador". Religião e Sociedade, 28(1):176-205.

SANSI, Roger. 2009. "'Fazer o santo': dom, iniciação e historicidade nas religiões afro-brasileiras". Análise Social, XLIV(1):139-160.

. 2011. "Images and persons in candomblé". Material Religion, 7(3):374393.

SANTANA, Esmeraldo Emeterio de. 1984. "Nação-Angola". In: Encontro de Nações de Candomblé. Salvador: Centro de Estudos Afro-Orientais-UFBA/Ianamá/Centro Editorial e Didático-UFBA. pp. 35-47.

SERRA, Ordep. 1978. Na trilha das crianças: os erês num terreiro angola. Dissertação de Mestrado, Brasília, Universidade de Brasília. . 1995. Águas do rei. Petrópolis: Vozes.

STENGERS, Isabelle. 2002 [1993]. A invenção das ciências modernas. Rio de Janeiro: Editora 34.

VERGER, Pierre. 1983. "A sociedade egbe òrun dos Abikü, as crianças nascem para morrer várias vezes". Afro-Ásia, 14:138-160.

VIVEIROS DE CASTRO, Eduardo. 2002. "Atualização e contra-efetuação do virtual: o processo do parentesco". In: A inconstância da alma selvagem. São Paulo: Cosac \& Naify. pp. 401-456.

WAFER, Jim. 1991. The taste of blood: spirit possession in brazilian candomblé. Philadelphia: University of Pennsylvania Press.

WAGNER, Roy. 1981 [1975]. The invention of culture. Chicago: The University of Chicago Press. 


\section{Resumo}

Partindo da conhecida oposição entre o que derivaria do "dom" e o que derivaria da "iniciação" nas religiões de matriz africana no Brasil, este trabalho visa, em um primeiro movimento, demonstrar etnograficamente que esse dualismo oculta um triadismo. O desdobramento da análise etnográfica levará, contudo e em seguida, à substituição desse triadismo por um modelo simultaneamente unitário e múltiplo. Neste, a "participação", em seus múltiplos sentidos, deverá ter um lugar ao lado do "dom" e da "iniciação", e as três categorias deverão ser entendidas como atualizações de um princípio subjacente único.

Palavras-chave Religiões Afro-brasileiras, Dom, Iniciação, Ritual, Cosmologia, Roy Wagner.

\section{Abstract}

Beginning with the known opposition between that which derives from the "gift" and that which derives from "initiation" in African-oriented religions in Brazil, this work aims to ethnographically demonstrate that said dualism actually conceals a triadism. The unfolding of ethnographic analysis in the article will, however, lead us to replace this triadism with a model that is simultaneously unified and multiple. In this, "participation" (in its multiple meanings) should have a place next to the "gift" and "initiation" and the three categories should be construed as updates of a single underlying principle.

Key words African-Brazilian Religions, Gift, Initiation, Ritual, Cosmology, Roy Wagner. 